\title{
The practices of mathematics education doctoral students
}

\section{JOHN MONAGHAN ${ }^{1}$}

\begin{abstract}
This paper looks at the practices (or praxeologies) of mathematics education doctoral students and their supervisors from the perspectives of activity theory and the anthropological theory of the didactic. The paper examines three ways to view mathematics education research before discussing: research methods and methodologies; the debate on qualitative and quantitative research ; and implications for the supervision of doctoral students.

Resumen. Este artículo observa las prácticas (o praxeologías) de estudiantes de doctorado en Educación Matemática y sus directores desde las perspectivas de la Teoría de la Actividad y de la Teoría Antropológica de lo Didáctico. El artículo examina tres modos de ver la investigación en Educación Matemática previa a la discusión: métodos de investigación y metodologías, el debate entre investigación cualitativa y cuantitativa y las implicaciones para la dirección de estudiantes de doctorado.
\end{abstract}

\section{Introduction}

This paper follows my invited to talk at CITAD 5 which I and the conference organisers agreed would be on the practices (praxeologies) of doctoral students and their supervisors. The talk and this paper is biased towards the practices of mathematics education (didactics) doctoral students as this is the area in which I am experienced. I am a British mathematics educator who has, for several decades, been greatly influenced by 'French didactics'. With regard to the anthropological theory of the didactic (ATD) I write as an 'ATD collaborator' rather than an 'ATD insider'. My paper is structured as follows. I begin with two short sections which set the scene: on my experience and understandings of ATD and of doctoral studies; and on doctoral studies themselves. I then present three ways to view mathematics education research (MER). My final section offer matters for discussion and I discuss: methods and methodology; what I call the qualitative-quantitative debate; and implications for doctoral supervision.

\section{My experiences and understandings}

Like any researcher, my interpretation of practices will be informed by my experiences and understandings, so I briefly comments on my understandings of the ATD and my experiences with doctoral students.

I was introduced to the ATD by Jean-baptiste Lagrange in the late 1990s. Jean-baptiste and I were both trying to understand the practices of mathematics teachers using digital technology. Jean-baptiste saw the ATD as a way of theorising these practices whereas I had started to use activity theory to do this. Over the decades I have mainly learnt about the ATD through discussing research with people (mainly French people) in the ATD camp. I read Chevallard (1999) in the early 2000s but I found it very difficult so it was nice to read Chevallard (2005) after hearing Yves Chevallard's CERME address. I find 'practice' - what people actually do as opposed to what they, perhaps, should do - extremely interesting and this is an important factor in my attempts to understand the ATD. I am not an expert in the ATD and I said this when I

\footnotetext{
${ }^{1}$ University of Agder, Norway, University of Leeds, UK - J.D.Monaghan@ education.leeds.ac.uk

El paradigma del cuestionamiento del mundo en la investigación y en la enseñanza

Eje 1. La TAD ante otros enfoques en didáctica
} 
received the invitation to speak at CITAD 5, but I think the organisers saw me as a 'sympathetic outsider' who might raise issues for discussion.

I have supervised 20 successful doctoral students (19 in the UK, 1 in Turkey) and 1 unsuccessful doctoral student (UK). I have 8 ongoing doctoral students (4 in the UK, 4 in Norway). I have examined doctoral students/theses in the Australia, France, Israel, Norway and the UK. There are similarities and differences in the theses with which I am familiar. With regard to similarities, there is a significant 'original research' dimension to each thesis and also some freedom for student choice of topic. Differences include: the title, e.g. $\mathrm{PhD}, \mathrm{EdD}$; fulltime or part-time study; the taught course-to-research ratio; whether the end product is a monograph or set of published academic papers with a commentary linking them together; the length when the thesis is a monograph; the emphases on theory and on methodology; the form of the viva and what precedes the viva. These differences suggest a set of related practices in doctoral study and supervision.

\section{On doctoral studies}

This is a second short section in which I position doctoral studies over time and at this moment in time.

In Medieval European universities study was organized in four faculties: basic - arts; higher - theology, medicine, and law. All faculties awarded intermediate degrees (bachelor) and final degrees (master and doctor - used interchangeably). The doctorates were awarded for advanced scholarship, not original research (no dissertation or original work was required). This situation changed in the early 19th century through the educational reforms in Germany, notably through the model of the University of Berlin. The arts faculty (the faculty of philosophy) started demanding contributions to research, backed by a dissertation, for the award of their final degree, which was labelled $\mathrm{PhD}$. These reforms proved extremely successful and the German universities started attracting foreign students, notably from the USA; American students would go to Germany to obtain a Ph.D. after having studied for a bachelor degree in American. In 1861 the University of Yale started granting the Ph.D. degree to students who, after having obtained the bachelor's degree, completed a course of graduate study and successfully defended a thesis containing original research in science or in the humanities. In the early $20^{\text {th }}$ century the $\mathrm{PhD}$ started spreading throughout the world ${ }^{2}$.

Kilpatrick (1992) charts the rise of doctorates in mathematics education over the $20^{\text {th }}$ century and the graph of the number of doctorates produced over time resembles an exponential curve with the steep rise starting in the 1960s. I have spoken of differences in doctorates above and will say more about differences in the following sections but I use the remainder of this section to speak of two other differences. The first in differences over time and I use myself as an example. I obtained my $\mathrm{PhD} 30$ years ago. This was a period when Piaget's influence was very strong in the English and French speaking developed nations. Many English language doctorates were influenced by Piagetian ideas and subsequent constructivist idea. The focus was individual cognition. The 1990s saw a change that Lerman (2000, p.23) refers to as 'the social turn', « the emergence into the mathematical education community of theories that see meaning, thinking, and reasoning as products of social activity ». Lerman, like me, is British and his

\footnotetext{
${ }^{2}$ The information set out in this paragraph was obtained from the Wikipedia entry Doctor of Philosophy.
} 
comments are biased to work of the Anglophone mathematical education community and I wonder if the ATD was a part of a social turn in the Francophone mathematical education community? This leads to my second distinction, the Anglophone community refers to 'mathematical education' whereas the Francophone community refers to 'the didactics of mathematics' - are they two terms for the same thing? I feel that 'mathematics education' is a broader term though my own research interests are in the didactics of mathematics. Whatever the answers to my questions are, mathematics education doctorates now employ many more theoretical (and methodological) approaches than were present when I did my doctorate.

\section{Three ways to view mathematics education research (MER)}

I want to pursue the question 'What is MER?' as MER is an essential feature of doctoral studies in mathematics education. I realise that my question could be taken as assuming that there is a unifying 'something' that characterises MER (when it is actually a collection of practices) but I retain it as an opening question. In addressing this question I want to consider things called 'methods' and 'methodology' as most doctoral students follow Research Methods courses prior to their research and most doctoral theses have a chapter called Methodology. A framework (explicit or implicit ... or a bit of both) is required to pursue the question. There are many ways to view MER and I focus on three which I value. I first briefly outline (a particular form of) activity theory which can be used to give a global view of MER. I then outline a much cited approach to theories by Luis Radford. Finally, I outline an ATD approach developed by Michéle Artigue, Marianna Bosch and Josep Gascón.

Activity theory (AT) is an approach to the study of human practices - any human practice and human practice in itself - whose roots go back to early Soviet psychology which was critical of psychology that explained states of consciousness in terms of consciousness and suggested that activity generates consciousness. «Activity» in AT is not just «doing something », but doing something for a purpose, the object of activity. Mediation is a central construct of AT for when people do something the doing is almost always mediated by other people, by tool use and by discourse and signs. The unit of analysis, that which preserves the essence of concrete practice, is also central to AT but activity theorists argue amongst themselves about what constitutes this 'essence'. A popular modern approach derives from Engeström (1987) where the unit of analysis is an activity system. Presentations of Engeström's version of AT often present Figure 1 as a visual aid for understanding the interrelations the 'parts' of the activity system. 


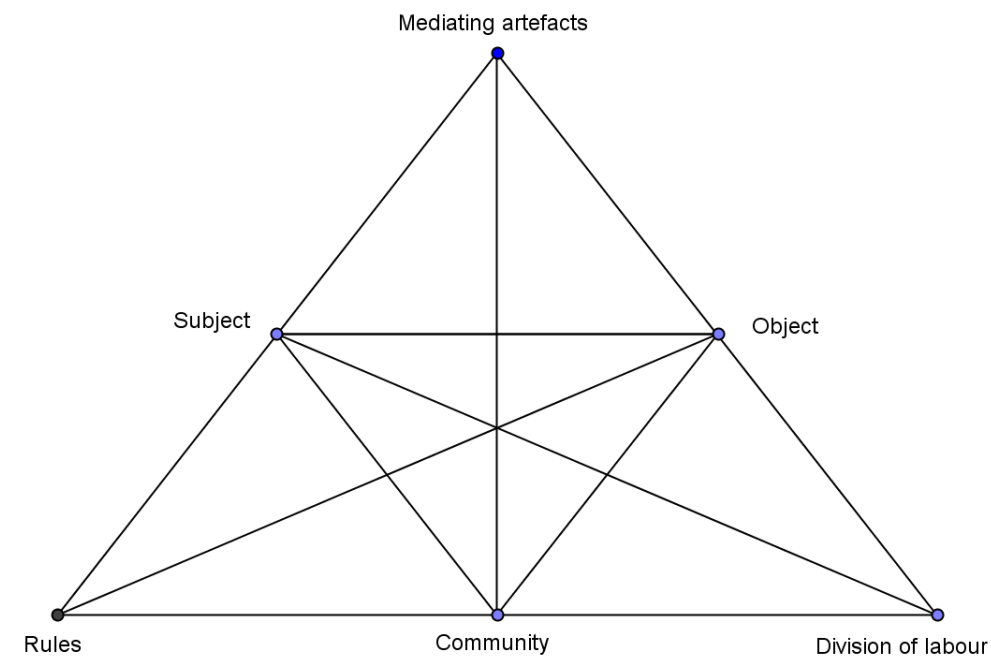

Figure 1. Engeström's expanded mediational triangle

Applying Figure 1 to MER, the subject is the researcher (novice or expert) and the object is to investigate a phenomenon which may generate new knowledge. S/he does this in communities (local and global) of other researchers. When the subject is a doctoral student: the rules of engagement must abide with institutional regulations (university requirements); and the division of labour is usually less distributed (beyond the subject) than it is with 'funded research' (which usually has a research team that already have their doctorates).

Figure 1 presents a global view but the triangles within Figure 1 allow a focus on specifics. For example, where are research methods, methodology and theories in Figure 1? I would place them at the 'mediating artefacts' node, focus on the subject-community-mediating artefact triangle and claim that the community mediates the subject's use of methods, methodology and theories. But a more detailed view of methods, methodology and theories is presented in a paper by an activity theorist, Luis Radford, who rarely refers to the Engeström model.

Radford (2008) was written in response to work on networking theories, not to address my question, but it does shed light on my question. It asserts that "a theory can be seen as a way of producing understandings and ways of action based on: ... basic principles ... a methodology ... paradigmatic research questions" (ibid., p.320). The principles (P) are a system of unequally weighted views and/or statements on pertinent constructs such as cognition, learning and social interaction. Radford emphasises that relationships between principles in theories by considering the relationship between cognition and social interaction in constructivism and in the Theory of Didactical Situations (TDS). Both theories view cognition in a Piagetian manner, as mental adaption, but the dialectic between cognition and social interaction social differ:

For constructivists ... the social realm is considered as a mere facilitator of the individual's development of these structures. In the Theory of Didactic Situations, cognition is also conceived of in an adaptive manner, but the social realm is thematized as a "milieu" and a game that the individual plays with it. (ibid., p.320)

Radford (ibid.) states that a 'methodology' (M), "includes techniques of data collection" and may go beyond 'positivistic' data collection. The word 'includes' suggests that there is more that can be said about a methodology - I agree! Further to this a methodology must: 
...fulfill at least two conditions: operability and coherence. Operability means that the methodology must be able to produce and deal with the data in such a way that "satisfactory" answers to the research questions are provided. ... Coherence means that the rhetoric of the argumentation of the methodology (be it statistical, discursive or other) is consistent with, and rests on, the chosen principles. (ibid., pp.321-322)

Paradigmatic research questions, Q, are « templates or schemas that generate specific questions as new interpretations arise or as principles are deepened, expanded or modified » (ibid., p.320). This suggests a "state of flux" in the development of theories and Radford clearly sees a dialectic between $\mathrm{P}, \mathrm{M}$ and $\mathrm{Q}$.

I am convinced by most of Radford's arguments on theories but there is more to be said of theories and one of these, which is relevant to considerations of doctoral students, concerns people and theories. I have argued that «theories cannot be separated from the people theorising » (Monaghan, 2010, p.16). In that paper I make seven statements related to this claim and the fifth is that there is a continuum with regard to theory expertise. For example, my understanding of the role of the milieu in TDS is certainly much less rich than Yves Chevallard's understanding. A similar difference will exist between doctoral students and supervisors' understanding of theories, constructs and methods (in most cases). It is not only understandings which may differ but the emphasis given to, say, constructs and methods may differ between doctoral student and supervisor; a doctoral student may be more concerned with a method for analysing data (and less focused on the problematique of the construct) than his/her supervisor. I now move on to the third and final ways to view MER which, like Radford (2008), was written in response to work on networking theories.

Artigue, Bosch \& Gascón (2011) consider research praxeologies. Given the focus of this special edition of Educaçao Mathemática Pesquissa, I shall assume that the reader is familiar with the language of ATD. Artigue et al. (2011, p.2) state:

... talking about 'theories' ... is the result of a metonymy used to point to the whole - research praxeologies - by only indicating one part, the theoretical block of praxeologies. ... The pair $[\mathrm{T} / \tau]$ corresponds to the 'practice' (or know-how) of research, with the types of problems $T$ that are approached and the techniques $\tau$ used to approach the problems. The block $[\theta / \Theta]$ forms the technological-theoretical discourse used to describe, justify and interpret both the research practice and the results obtained. This theoretical block corresponds to research 'knowledge' ...

Artigue et al. (2011) pay special attention to 'phenomena' and 'didactic phenomena' in particular, «empirical facts, regularities that arise through the study of research problems » (ibid., p.3). The 'didactic transposition' is an instance of a phenomenon. Artigue et al. (2011) discuss phenomena in relations to the elements, $T / \tau / \theta / \Theta$, of a praxeology. This has implications for a consideration of doctoral students and MER because phenomena may generate research questions "that could not even have been formulated before the identification of the phenomenon" (ibid., p.4) and "new technological results that partially become new theoretical tools and produce in turn new research techniques allowing the identification or construction of new phenomena" (ibid., p.5).

With regard to 'methods' and 'methodology', Artigue et al. (2011) do not use the term 'methods' but do use the term 'methodology'. I consider their use of this term in the opening of the next section. Artigue et al. (2011) view their approach as «fully coherent with that 
developed by Radford (2008) » but note "the word phenomenon is absent from Radford's text" (ibid., p.9).

\section{Discussion}

In this section I offer matters for discussion which I consider (i) do not have easy answers and (ii) would interest my an ATD audience. I offer these issues in the spirit that my audience and I can learn from each other rather than offering my audience ready-made answers. My first issue takes up the 'methods and methodology' theme introduced at the end of the last section. My second issue concerns what I call the 'qualitative-quantitative debate'. My last issue considers how an understanding of mathematics education doctoral practices might help supervisors to become better supervisors.

\subsection{Methods and methodology}

With regard to research, what is the difference between methods and methodologies? I start with reflections on my own experience and then consider Radford (2008) and Artigue et al. (2011) before bringing doctoral students into the discussion.

A methodology (to me) is an approach (an attack strategy) to research that is consistent with the theoretical framework that underpins the research and assists in formulating the research questions. Methods (to me) are means of addressing the research questions and invariably (though not necessarily) involve considerations of data to be collected and analysed and techniques of analysis. In ATD terms I think this puts methods in the praxis-technique element of a praxeology and methodology in the logos-technology element. I think the description I have outlined applies to research I design to further my own interests and the research of my doctoral students who regard me as a mentor. I think it does not apply (in such a simple manner) when my approach is in response to an 'invitation to tender' to conduct research from, say, a government agency or to my doctoral students who regard me as a facilitator towards a qualification; when I response to an 'invitation to tender' the methods the sponsors expect me to use are often part of the tender. From a praxeological point of view it would seem that I adopt different praxeologies depending on the source (myself or a funding agency) of the perceived need for the research. From an AT point of view, the objective of the activity is less clear when I apply for funded research because I am trying to align a personal objective to the objective of the funders. Perhaps the two points of view could both inform the research knowledge at stake when I (or any researcher) engage in specific funded research.

But I think that my focus on 'methods' and 'methodology' arises partly from my past experiences; my UK doctoral students had to enrol in modules with names such as 'Qualitative Research Methods' and 'Quantitative Research Methods I' and when I applied for UK funded research, the forms I had to complete contained the term 'research methods'. It is interesting to note that Artigue et al. (2011) uses the terms 'methodology' and 'methodological' but does not use the term 'method'. Radford (2008) is similar though he does use the term 'method' twice (once with regard to 'statistical methods' and once in a passing reference to the methods of Liberal economy). Nevertheless, I believe that my reflections above on methods and methodology are consistent with the expositions by Radford (2008) and by Artigue et al. (2011) and I shall now briefly consider this claim. 
As I pointed out above, Radford (208, p.320) states that a methodology « includes techniques of data collection». I interpret this as short for «includes techniques of data collection and analysis », in which case 'techniques' are what I have been calling 'methods'. Similarly Artigue et al. (2011) appear to use the term 'technique' are what I call a 'method'

I am now going to make a potentially controversial generalisation: Anglophone MER $^{3}$ often emphasises exact methods (and does not seriously attend to logos-related methodology) whereas Francophone MER often pays close attention to the methodology (and does not attend to 'standards of rigour' of the methods as much as some Anglophone researchers would expect). If there is some truth in this generalisation, then there will be a lot of ME doctoral students who enter their doctoral studies with an implicit emphasis on either the logos pair or the praxis pair of their research praxeology simply because of the research environment of the university they are in. Please note that in saying this I am not talking about qualitative vs quantitative research as a focus on methods over methodology applies to both qualitative and quantitative methods. I now, however, move on to consider qualitative vs quantitative research.

\subsection{The qualitative-quantitative debate}

The 'qualitative-quantitative debate' is my term for a battle of ideas with regard to research methods. On one side there is a perception that quantitative research provides 'hard evidence' and attends to 'scientific rigour' whilst qualitative research provides 'soft evidence' and does not conform to the expectations of 'scientific rigour'. I do not share this perception and my research includes qualitative research, quantitative research and what is called 'mixed methods' research (i.e. it employs both qualitative and quantitative research). But it is clear that some (powerful) people do have this perception. In 2008, an important Report (National Mathematics Advisory Panel, 2008) was published, «to foster greater knowledge of and improved understanding in mathematics among American students » (ibid., p.xiii). In its recommendation regarding the soundness of research methods the Report generated three categories of studies, the first (and highest) is «studies that test hypotheses, meet the highest methodological standards (internal validity), and have been replicated with diverse samples ... » (ibid., p.7-4) ${ }^{4}$. Moving from the USA to the UK there is a perception in the UK that the UK government is influenced by USA government initiatives and ideas. Whatever the case, a few years after the National Mathematics Advisory Panel Report the UK Department for Education decided to prioritise quantitative research and randomised control trials in particular. The following is an example of an invitation to tender from $2013^{5}$. The Multiplicative reasoning cluster randomised control trial to evaluate an initiative focused on multiplicative reasoning in 11-14 year old students. The research design was given, «The 60 participating schools will be randomly assigned to become intervention of control schools ... Outcome data will be collected in all 60 schools in June 2014. » Not only was the research design given but the tests that would 'measure progress' were given and a significant factor in the selection of the team to conduct the research was a track record in randomised control trial research. I think this is related, in a

\footnotetext{
${ }^{3}$ I also include MER in nations which emulate Anglophone MER.

${ }^{4}$ It is worth noting that Educational Researcher, the official journal of the American Educational Research Association, published a Special Issue (Vol. 37, No.9) in which prominent mathematics education researchers reacted to the National Mathematics Advisory Panel Report.

${ }^{5}$ ISRCTN63650913, doi 10.1186/ ISRCTN63650913
} 
research setting, to what Yves Chevallard calls to as 'monumentalism' (but applied to research methods).

But the qualitative vs quantitative debate is not completely one-sided. The academic journal Basic and Applied Social Psychology recently (see the Editorial in Vol. 37, 1-26) announced a policy to effectively ban future papers using the Null Hypothesis Significance Testing paradigm (NHSTP); papers using this paradigm will not be rejected automatically but if they are accepted then "authors will have to remove all vestiges of the NHSTP ( $p$-values, $t$-values, $F$-values,,", (ibid.). The position of the editors appears to me not so much an issue with the methods as it is with its use by some researchers - to ascribe 'causal mechanisms' from the occurrence of a statistically significant $p$-value. This ban has not gone unnoticed by statisticians; the responses from the American Statistical Association and the Royal Statistical Society (RSS) are similar, «This policy may have its own negative consequences and thus the proper use of inferential methods needs to be analyzed and debated in the larger research community. » (RSS statement available on http://www.statslife.org.uk/news/2116-academic-journal-bans-p-valuesignificance-test).

The qualitative vs quantitative debate is a debate over praxeologies that doctoral students should engage with, not to 'take a side' but to evaluate the arguments - which could be turned on their research. Not attending to this debate poses potential problems for their future as researchers. I illustrate this with three examples from my experience. The first is seeing social significance (and, worse still, 'causal mechanisms') where there is simply statistical significance. I have, over a long period, asked doctoral students who appeared to have unwarranted beliefs in $p$-values, "If I repeat a random experiment 20 times and I get a result with $p \leq 0.05$ in one of these experiments, then should I regard this as important?". The answer is invariably 'yes' when, statistically, we can expect 1 in 20 repeated experiments to yield a significant result at the 5\% level. The second example is putting research methods before research questions in a proposal for doctoral studies ${ }^{7}$. I have, over the years, read hundreds of doctoral proposals and I would estimate that this 'error' has been present in $10 \%$ of these proposals; for example, stating that pre-, post- and delayed post-tests will be used and analysed by using, say, the Mann-Whitney U test, before stating the research questions that this test will be used to address. This may simply be a mistake that novices fall in to but it may reflect deeper cultural values associated with research praxeologies, which brings me to my third example. There is, from the proposals for doctoral studies I have read, a certain area of the world (which I will not name for reasons of politeness) where the use of quantitative methods associated with a quasi-experimental methodology ${ }^{8}$ is the norm. Now I do not deny that there is research for which this methods-methodology mix is appropriate but is a regional dominant research praxeology ever a good thing? From the way I have reported this example you can guess that I do not view this 'quantitative methods associated with a quasi-experimental methodology norm' as a good thing but do ATD researchers regard one dominant research praxeology as a good thing?

\footnotetext{
${ }^{6}$ Available at http://www.tandfonline.com/doi/pdf/10.1080/01973533.2015.1012991

7 This example, in itself, does not concern qualitative vs quantitative issues but I have only noticed it in proposals outlining a quantitative methodology.

${ }^{8}$ i.e. comparing a control and an experimental group of students or teachers.
} 


\subsection{Implications for mathematics education doctoral supervisors}

As stated in the opening paragraph of this section, this sub-section concerns how an understanding of mathematics education doctoral practices might help supervisors to improve their practices. But I'd like to start by saying that I think that most of what I have said above applies to most education doctoral students. There are, perhaps, some special circumstances that apply to mathematics education doctoral students: they have often crossed disciplines - the 'disciplinary gap' between a degree in mathematics and a doctorate in mathematics education seems greater than that between a degree in sociology and a doctorate in the sociology of education; mathematics education doctoral students should, by virtue of their mathematical backgrounds, be better prepared to engage with the qualitative vs quantitative debate than less mathematically experienced education doctoral students.

Recognising different practices/praxeologies in doctoral studies is important for supervisors. Doctoral studies are supposed to advance scientific knowledge and a supervisor assuming that this is simply done in the way s/he did her/his doctorate seems to work against knowledge generation. Similarly recognising different practices and underlying theoretical paradigms in different areas of the world (such as a positivist paradigm that values quantitative methods associated with a quasi-experimental methodology) is important for someone who supervises doctoral students from many nations. But tensions between students and supervisors can arise even when both have similar backgrounds. Engeström's version of AT alerts us to this. Both nested triangles in Figure 2 are replicas of Figure 1; the left one for the student, the right one for the supervisor. There will be differences as well as similarities in the component parts (rules, community, etc) of the activity systems and tensions could/will arise if there are significant differences in the object of each activity system.
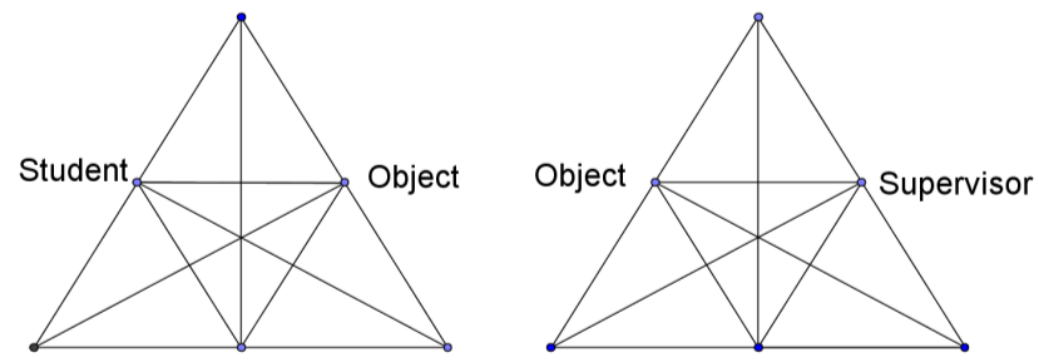

Figure 2. The activity systems of a doctoral student and her/his supervisor

But aligning the objects of activity of two systems/people is not an easy task and it is certainly not simply a case of the more experienced telling the less experienced what to think. It is a journey into what Vygotsky (1978) calls the zone of proximal development and the journey is a cultural one - getting a novice to appropriate a cultural artefact and practice. This is hard enough in mathematics teaching when the teacher has a very good understanding of the mathematics in question (for example, functions) but a complication in doctoral supervision is that there is no really knows quite what the object is; students can be pointed to university regulations and supervisors can pass copies of past doctoral theses to new students but there is no Aristotelean essence to the thing we call a doctoral thesis. I have no simple solutions to offer but one approach is to view this journey as a joint one into a shared zone of proximal development - and this, in my opinion, makes doctoral supervision a didactic task. 
My final words concern the potential of ATD to improve supervisor practice through its work on study and research courses (SRC). Many readers will know this work much better than $\mathrm{me}^{9}$. The aim of SRC is «to put the important and meaningful questions at the forefront of teaching » (Winsløw, Matheron \& Mercier, 2013, p.269) but surely this approach lends itself to developing important and meaningful doctoral research questions. It would be very interesting to research how this is actually done in doctoral supervision practice. I suspect that the SRC tree diagrams that Winsløw et al. (2013) present, with questions and answers, would be augmented to tree diagrams with questions, methods and answers. It could pave the way for a new branch of epistemology, the epistemology of design for knowledge generation.

\section{References}

Artigue, M., Bosch, M. \& Gascón, J. (2011). Research praxeologies and networking theories. Paper presented at CERME 7: Working Group 16, Different theoretical perspectives and approaches in research in mathematics education. Available at http://www.cerme7. univ.rzeszow.plWG/16/CERME7_WG16_Artigue.pdf

Chevallard, Y. (1999). L'analyse des pratiques enseignantes en théorie anthropologique du didactique. Recherches en Didactique des Mathématique, 19(2), 221-266.

Chevallard, Y. (2005). Steps towards a new epistemology in mathematics education. In M. Bosch (Ed.), Proceedings of the 4th Congress of the European Society for Research in Mathematics Education (pp. 21-30). Barcelona: Universitat Ramon Llull.

Engeström, Y. (1987). Learning by expanding: An activity-theoretical approach to developmental research. Available at http://lchc.ucsd.edu/mca/Paper/Engestrom/Learningby-Expanding.pdf

Kilpatrick, J. (1992). A history of research in mathematics education. PP._ in D. A Grouws,. (Ed.). Handbook of research on mathematics teaching and learning: A project of the National Council of Teachers of Mathematics. Macmillan Publishing Co, Inc.

Lerman, S. (2000). The social turn in mathematics education research. Multiple perspectives on mathematics teaching and learning, 19-44.

National Mathematics Advisory Panel (2008). Foundations for success: The final report of the National Mathematics Advisory Panel. Washington, DC: U.S. Department of Education.

Vygotsky, L. S. (1978). Mind in Society. Harvard University Press. Cambridge, MA.

Radford, L. (2008). Connecting theories in mathematics education: Challenges and possibilities, ZDM, 40, 317-327.

Winsløw, C., Matheron, Yves \& Mercier A. (2013). Study and research courses as an epistemological model for didactics. Educational Studies in Mathematics 83, nº. 2, 267-284.

\footnotetext{
${ }^{9}$ I know about this approach through reading Chevallard (2005) and Winsløw, Matheron \& Mercier (2013).
} 